\title{
POSITIVE SOLUTIONS FOR CONTINUOUS AND DISCRETE BOUNDARY VALUE PROBLEMS TO THE ONE-DIMENSION $p$-LAPLACIAN
}

\author{
Daqing Jiang, Jifeng Chu, Donal O’Regan and R. P. Agarwal
}

\begin{abstract}
New existence results (for positive solutions) for continuous and discrete boundary value problems to the one-dimension $p$-Laplacian are presented in this paper. Here we use a well-known fixed point theorem in cones. Our results improve several recent results established in the literature.
\end{abstract}

\section{Mathematics subject classification (2000): 34B15, 39A10.}

Key words and phrases: positive solutions, continuous and discrete boundary value problem, $p$ Laplacian, fixed point theorem in cones.

\section{REFERENCES}

[1] R. P. Agarwal and D. O'Regan, Nonpositive discrete boundary value problems, Nonlinear Analysis, 39 (2000), 207-215.

[2] R. P. AgaRWAL AND D. O'Regan, Boundary value problems for discrete equations, Appl. Math. Letters, 10 (1997), 83-89.

[3] R. P. Agarwal, D. O'Regan And P. J. Y. Wong, Positive solutions of differential, difference and integral equations, Kluwer Acad. Publ, Dordrecht, (1999).

[4] R. P. Agarwal And D. O'Regan, Singular discrete boundary value problems, Appl. Math. Letters, 12 (1999), 127-131.

[5] R. P. Agarwal, H. Lu AND D. O'Regan, Eigenvalues and the one-dimensional p-Laplacian, Journal of Mathematics Analysis and Applications, 266 (2002), 383-400.

[6] A. Ben-NAOUm AND C. De Coster, On the existence and multiplicity of positive solutions of the p-Laplacian separated boundary value problems, Differential and Integral Equations, 10 (1997), $1093-1112$.

[7] D. DUNNINGER AND H. WANG, Multiplicity of positive radial solutions for an elliptic system on an annulus, Nonlinear Analysis, 42 (2000), 803-811.

[8] D. DUNNINGER AND H. WANG, Existence and multiplicity of positive radial solutions for elliptic systems, Nonlinear Analysis, 29 (1997), 1051-1060.

[9] C. De Coster, Pairs of positive solutions for the one-dimensional p-Laplacian, Nonlinear Analysis, 23 (1994), 669-681.

[10] K. DeImLing, Nonlinear Functional Analysis, Springer, Berlin, (1985).

[11] L. ERBE, S. HU AND H. WANG, Multiple positive solutions of some boundary value problems, Journal of Mathematics Analysis and Applications, 184 (1994), 743-748.

[12] L. KONG AND J. WANG, Multiple positive solutions for the one-dimensional p-Laplacian, Nonlinear Anal. 42 (2000), 1327-1333.

[13] D. O'REGAN, Some general existence principles and results for $\left[\phi\left(y^{\prime}\right)\right]^{\prime}=q(t) f\left(t, y, y^{\prime}\right),(0<t<1)$, SIAM J. Math. Anal. 24 (1993), 648-668.

[14] D. O'Regan, Existence Theory for Nonlinear Ordinary Differential Equations, Kluwer Academic, Dordrecht, 1997.

[15] H. WANG, On the existence, multiplicity and nonexistence of positive solutions of boundary value problems involving the $p$-Laplacian, submitted. 
[16] J. Y. WANG, The existence of positive solutions for the one-dimensional p-Laplacian, Proc. Amer. Math. Soc. 125 (1997), 2275-2283.

[17] J. WANG, W. GAO AND Z. LIN, Boundary value problems for general second order equations and similarity solutions to the Rayleigh problem, Tohoku Math. J. 47 (1995), 327-344.

[18] H. WANG, On the existence of positive solutions for semilinear elliptic equations in the annulus, J. Differential Equations, 109 (1994), 1-7.

[19] D. Q. JIANG AND W. GAO, Upper and lower solution method and a singular boundary value problem for the one-dimension p-Laplacian, J. Math. Anal. Appl. 252 (2000), 631-648.

[20] D. Q. JIANG, Upper and lower solutions method and a superlinear singular boundary value problem for the one-dimension p-Laplacian, Computers and Mathematics with Applications, 42 (2001), 927-940.

[21] D. Q. JIANG AND H. LIU, On the existence of nonnegative radial solutions for P-Laplacian elliptic systems, Ann. Polon. Math. LXXI.1 (1999), 19-29.

[22] D. Q. JIANG, P. Y. PANG AND R. P. AgARWAL, Upper and lower solutions method and a superlinear singular discrete boundary value problem, Dynamics Systems and Applications, to appear.

[23] D. Q. JiAnG, L. ZHANG, D. O'REgAN AND R. P. AgARWAL, Existence theory for single and multiple solutions to singular positone discrete Dirichlet boundary value problems to the one-dimension p-Laplacian, 13 (2003), 179-199.

[24] KunQuan Lan AND JeFFrey R. L. WebB, Positive solutions of semilinear differential equations with singularities, J. Differential Equations, 148 (1998), 407-421. 